\title{
Лоншакова С.A. \\ Проблемы исполнения федеральных целевых программ при решении государственных задач
}

ФГБОУ ВО «МГУ им. Н. П. Огарёва»

(Россия, Саранск)

doi: $10.18411 / \mathrm{lj}-06-2021-275$

\section{Аннотация}

Предметом настоящей статьи является выявление проблем исполнения федеральных целевых программ. Уделено внимание наиболее актуальным проблемам на основе ежегодного доклада Минэкономразвития РФ по реализации ФЦП за 2020 год. Цель статьи - выявить проблемы исполнения ФЦП и предложить варианты решения. Актуальность статьи обосновывается важностью решаемых государственных задач посредством программно-целевого планирования.

Ключевые слова: федеральная целевая программа, государственный заказчик, прогнозирование, эффективность, финансирование, ценообразование.

\section{Abstract}

The subject of this article is to identify problems in the implementation of federal target programs. Attention is paid to the most pressing problems on the basis of the annual report of the Ministry of Economic Development of the Russian Federation on the implementation of federal target programs for 2020. The purpose of the article is to identify problems in the implementation of federal target programs and to offer solutions. The relevance of the article is substantiated by the importance of the state tasks being solved through program-target planning.

pricing.

Keywords: federal target program, state customer, forecasting, efficiency, financing,

Исходя из определения федеральной целевой программы как главного инструмента Правительства Российской Федерации по реализации задач научнотехнической и инновационной политики, а также активного воздействия на социальноэкономическое развитие России, можно сделать вывод о важности выявления и решения проблем исполнения ФЦП. Анализировать проблемы исполнения федеральных целевых программ нужно по следующим причинам:

— конечный результат ФЦП - решение важной государственной задачи;

- достижение запланированного результата ФЦП = эффективное расходование бюджетных средств.

В ежегодном докладе Минэкономразвития «О ходе реализации федеральной адресной инвестиционной программы и выполнения федеральных целевых программ за 2020 год» представлены сведения об итогах реализации целевых программ, в том числе дана оценка их эффективности. Среди причин недостаточно высокой эффективности можно выделить наиболее главную - корректировки ФЦП проходят очень медленно ввиду присутствия административного ресурса и торможения процесса с его стороны. Целевые программы утверждаются постановлениями Правительства РФ. Таким образом, любые изменения в них также должны быть утверждены постановлениями Правительства РФ, что теоретически обеспечивает стабильность финансирования.

Дело в том, что государственные заказчики при подготовке программ закладывают значительные объемы средств из внебюджетных источников и средств бюджетов субъектов Российской Федерации, мотивируя это значимостью данного аргумента в пользу принятия программы. 
На уровне действующих нормативно-правовых актов в России в настоящее время не установлена обязанность государственного заказчика по включению средств субъектов РФ и внебюджетных источников на реализацию федеральных целевых программ. Согласно пункту 10.1 раздела 3 Порядка разработки и реализации федеральных целевых программ и межгосударственных целевых программ, в осуществлении которых участвует Российская Федерация, утвержденного Постановлением Правительства от 26.06.1995 № 594 «О реализации Федерального закона "О поставках продукции для федеральных государственных нужд», федеральные целевые программы должны содержать сведения о распределении объемов и источников финансирования по годам за счет всех источников [4]. В ходе внесения проекта федерального закона о федеральном бюджете на очередной финансовый год и плановый период Правительство Российской Федерации вносит в Государственную Думу проект федерального закона о бюджетах государственных внебюджетных фондов Российской Федерации на очередной финансовый год и плановый период вместе с реестром расходных обязательств субъектов РФ по обязательствам, возникающим при выполнении полномочий Российской Федерации, в том числе при реализации федеральных целевых программ (статья 12 Бюджетного Кодекса РФ) [3].

Данный факт допускает возможность фактического пересмотра финансовых показателей программ ежегодно. Изменение параметров финансирования приводит к необходимости корректировки целей и задач, смещения сроков реализации программных мероприятий в сторону их увеличения.

Анализируя годовой доклад Минэкономразвития и данные с сайта fcp.economy.gov.ru, я пришла к выводу о следующих наиболее значимых проблемах, выявленных в процессе реализации целевых программ:

1. Недостаточное финансирование федеральных целевых программ за счет средств федерального бюджета в общей структуре источников финансирования целевых программ. Высокая доля в источниках финансирования внебюджетных средств позволяет предположить, что сегодняшние целевые программы являются иным выражением специфических внебюджетных фондов.

Согласно данным доклада Минэкономразвития за 2020 год по восьми ФЦП финансирование программных мероприятий за счет средств бюджетов субъектов Российской Федерации и местных бюджетов, а также средств внебюджетных источников за 2020 год оказалось выше среднего уровня привлеченных средств (от $443,1 \%$ до $100,3 \%$ ).

Необходимо отметить постепенное снижение объемов финансирования федеральных целевых программ за счет средств федерального бюджета и общего объема расходов федерального бюджета в ВВП. В целом по сравнению с 2015 годом объем бюджетного финансирования уменьшился на $60 \%$, доля расходной части федерального бюджета в ВВП уменьшилась с $0,7 \%$ до 0,2\% [6].

Привлечение средств бюджетов субъектов Российской Федерации и местных бюджетов, а также средств внебюджетных источников отражается в виде значительной финансовой нагрузки на регионы и предприятия, и как следствие, недостижение или недостаточное достижение запланированных целевых показателей ФЦП.

Для решения данной проблемы предлагаю установить на законодательном уровне допустимое процентное соотношение объема федерального финансирования к объему финансирования за счет иных источников. Таким образом, в случае необходимости привлечения дополнительных средств в процессе исполнения федеральной целевой программы необходимо будет внести предложения о корректировке финансовой части ФЦП в равных долях, чтобы соблюсти установленное соотношение средств федерального бюджета к иным источникам. 
2. Отсутствует комплексный подход оценки эффективности реализации государственных программ.

В Сводном годовом докладе содержится информация о кассовом исполнении госпрограмм в разрезе источников ресурсного обеспечения. Однако Методика, примененная Минэкономразвития России, не предусматривает оценку исполнения расходов за счет всех источников финансирования.

По данным Минфина России (письмо от 5 февраля 2021 г. № 16-08-04/7851) и Федерального казначейства (письмо от 5 февраля 2021 г. № 02-01-03/2147), по итогам 2020 года кассовое исполнение ФЦП из средств федерального бюджета составило $84,4 \%$ от бюджетных назначений на 2020 год, а за 2019 год составил 72,0 \% от бюджетных назначений на 2019 год [6].

Учитывая, что расходы на реализацию госпрограмм за счет внебюджетных источников и бюджетов субъектов Российской Федерации в 2021 году запланированы по 7 из 11 госпрограмм, полагаю, что в интегральную оценку целесообразно включать оценку выполнения расходных обязательств за счет всех источников финансового обеспечения всеми участниками госпрограмм с учетом финансирования бюджетов субъектов Российской Федерации и внебюджетных источников.

3. Низкое качество разрабатываемой проектно-сметной документации на объекты капитального строительства. Данное обстоятельство влечет за собой корректировки ФЦП одновременно по двум критериям: в части финансирования и в части изменения физических и функциональных показателей объекта капитального строительства.

Согласно докладу Минэкономразвития по итогам 2020 года данное обстоятельство явилось причиной недостижения целевых индикаторов по ряду ФЦП, из них - «Развитие водохозяйственного комплекса Российской Федерации в 2012-2020 годах», «Охрана озера Байкал и социально-экономическое развитие Байкальской природной территории на 2012-2020 годы», «Социально-экономическое развитие Курильских островов на 2016-2025 годы» [6].

Согласно части 5 статьи 49 Градостроительного Кодекса РФ предметом государственной экспертизы проектной документации является оценка соответствия проектной документации требованиям технических регламентов, а также результатам инженерных изысканий.

Таким образом, минимизировать риски разработки некачественной проектной документации возможно, усилив ответственность федеральных органов исполнительной власти, органов исполнительной власти субъектов Российской Федерации, уполномоченных на проведение государственной экспертизы проектной документации, и подведомственных указанным органам государственных учреждений. Учитывая, что объём капитальных вложений в 2021 году в разрезе общего объема финансирования согласно данным с сайта fcp.economy.gov.ru составляет примерно 48 \%, предлагаю включить в годовой доклад Минэкономразвития раздел об оценке действиям обозначенных выше органов государственной власти в части неэффективной работы на этапе государственной экспертизы.

4. Недостаточно эффективная работа государственных заказчиков в отношении генеральных подрядчиков, головных исполнителей и поставщиков по государственным контрактам, сроки исполнения по которым сорваны. Несвоевременное применение договорных санкций, а также бездействие заказчиков в отношении подрядчиков/поставщиков/исполнителей приводит к увеличению сроков реализации ФЦП.

С другой стороны существующее законодательство в области государственных закупок несовершенно в части предоставления заказчику права быстрого маневрирования в отношении «нерадивого» исполнителя. Так, согласно нормам Федерального закона от 05.04.2013 № 44-Ф3 "О контрактной системе в сфере закупок 
товаров, работ, услуг для обеспечения государственных и муниципальных нужд", существует определенный порядок расторжения в одностороннем порядке государственного контракта с исполнителем. Данный порядок предусматривает значительный временной промежуток процедуры расторжения (более 1 месяца). Нарушение процедуры расторжения контракта чревато для заказчика административной ответственностью.

Согласно докладу Минэкономразвития за 2020 год данные обстоятельства явились причиной недостижения целевых показателей по следующим федеральным целевым программам: «Охрана озера Байкал и социально-экономическое развитие Байкальской природной территории на 2012-2020 годы», «Развитие водохозяйственного комплекса Российской Федерации в 2012-2020 годах», «Развитие Республики Карелия на период до 2021 года» [5].

В данной проблеме сможет помочь введение административной и уголовной ответственности со стороны подрядчика/поставщика/исполнителя в случае срыва по его вине сроков реализации федеральной целевой программы.

5. Неэффективное целеполагание при подготовке проекта ФЦП. От того, насколько корректно, реально поставлены цели, как они увязаны с решаемыми проблемами и возможностями ресурсного обеспечения, в первую очередь зависит успешность, надежность, результативность программно-целевого планирования и управления [8, 34-35]. Неправильный выбор целей при создании системы приводит к тому, что решаются не те проблемы, которые должны решаться. Это может привести к гораздо большему ущербу, чем применение неэффективной системы для достижения выбранных целей $[7,43]$.

Корректная расстановка целей зачастую зависит не только от профессионализма должностных лиц, но также и от постоянно изменяющихся внешних условий и факторов, среди которых примером послужила пандемия новой короновирусной инфекции в 2020 году. Она отражена как первопричина невыполнения целевых показателей практически всех действующих федеральных целевых программ в 2020 году [5].

Реализация федеральных целевых программ рассчитана на период от 5 до 10 лет. Как правило, эффективное целеполагание на такой период времени не представляется возможным. Необходимо поставить приоритеты краткосрочного планирования перед долгосрочным для повышения гибкости программ и возможности принимать более оперативные решения о корректировке и финансировании программ.

6. Недостаточно развитый механизм прогнозирования в России. Говоря о прогнозировании, стоит отметить его достаточную эффективность и успешность для дальнейшего принятия стратегических решений, что очень важно в применении программно-целевого подхода при реализации ФЦП.

В Правилах разработки прогноза социально-экономического развития Российской Федерации, утвержденных Постановлением Правительства РФ от 22.07.2009 № 596 "О порядке разработки прогноза социально-экономического развития Российской Федерации", указано, что прогнозы разрабатываются на долгосрочную (10 лет), среднесрочную (3-5 лет) и краткосрочную (1 год) перспективу. Прогнозы разрабатываются по сферам деятельности, по территориальному горизонту. В зависимости от влияния внешних и внутренних факторов формируется несколько вариантов прогноза. Более конкретно порядок разработки государственных прогнозов должен определяться Правительством Российской Федерации, однако среди известных опубликованных правительственных нормативно-правовых актов подобный документ не представлен [1].

Пути решения проблемы финансового прогнозирования и его совершенствования лежат в развитии институтов прогнозирования и ведения активного мониторинга планового процесса в России. 
7. Несовершенство действующей методологии оценки эффективности государственных программ Российской Федерации. Исходя из положений доклада Минэкономразвития за 2020 год, можно отметить некорректно выбранные показатели для оценки, которые в итоге при оценке реализации ряда программ стали невыполнимы.

Так, по ФЦП «Охрана озера Байкал и социально-экономическое развитие Байкальской природной территории на 2012-2020 годы» по итогам 2020 года из девяти целевых индикаторов и показателей плановые значения достигнуты по одной позиции («Количество выпускаемых водных биологических ресурсов») [6].

Показатель «Отношение площади особо охраняемых природных территорий, пройденной пожарами, к количеству пожаров» превышает в 2,5 раза запланированный (что в данном контексте несет отрицательный эффект) по причине сложных климатических условий местности. Показатель «Отношение количества посещений особо охраняемых природных территорий к их рекреационной емкости» не достигнут в связи с тем, что отсутствует единая методическая основа для определения рекреационной емкости особо охраняемых природных территорий (ООПТ), в связи с чем в различных ООПТ показатели рекреационной емкости различаются на порядок.

Достижение запланированного результата по данным показателям не предполагалось возможным еще на этапе формирования программы, что говорит о неэффективной работе органов государственной власти на этапе формирования программы и неверном отборе критериев для оценки эффективности ФЦП.

8. Неэффективное ценообразование в области государственного оборонного заказа.

«Войны» заказчиков и исполнителей, связанные с недовольством обеих сторон при применении действующих методик расчета цен на продукцию для ГОЗ, периодически обостряются, о чем свидетельствуют новостные ленты. При этом недовольство заказчиков связано с высокими ценами (расходы на ГОЗ часто превышают инфляцию в разы). В результате бюджетные средства расходуются неэффективно. А недовольство исполнителей связано с тем, что цена часто не покрывает издержки на производство продукции, не обеспечивает конкурентность заработной платы и выгодность производства продукции по ГОЗ [2]. Причина этих «войн» лежит в монополизации производителей продукции по ГОЗ и в монополизации государственных заказчиков такой продукции. Рынка как такового здесь нет. Есть единственные исполнители по государственному оборонному заказу и весьма ограниченное количество государственных заказчиков такой продукции.

Bce предпринимаемые на данный момент попытки Правительства РФ в части регулирования цен по ГОЗ носят фискальную, но никак не стимулирующую направленность. Следует также отметить несоответствие нормативной базы, а именно 44-Ф3 (Федерального закона "О контрактной системе в сфере закупок товаров, работ, услуг для обеспечения государственных и муниципальных нужд") и 275-Ф3 (Федерального закона "О государственном оборонном заказе") в части подходов к ценообразованию в связи с тем, что военная продукция носит не рыночный, а сложный и инновационный характер [2].

Требуется создание абсолютно новой системы ценообразования, которая коренным образом реорганизует структуру системы ценообразования, привлечет к решению вопросов ценообразования специалистов по инвестиционному анализу, страхованию контрактных рисков, потребует разработки нового методического аппарата.

$$
* * *
$$

1. Бородушко И.В. Стратегическое планирование и контроллинг // [Электронный ресурс] - Режим доступа. - URL: https://marketing.wikireading.ru/18375/.- Текст: электронный 
2. Мельников Г. Цена обороны и оборона цены. О кризисе ценообразования в сфере гособоронзаказа и путях решения проблем// Независимое военное обозрение - [Электронный ресурс] - Режим доступа. - URL: https://nvo.ng.ru/concepts/2018-08-16/10_1009_gosoboron.html/.- Текст: электронный

3. Российская Федерация. Нормативные документы. Бюджетный Кодекс Российской Федерации [принят Федеральным Законом от 31.07.1998 года № 145-Ф3] - Доступ из справ.-правовой системы «Консультант-Плюс». - URL: http://www.consultant.ru/document/cons_doc_LAW_19702/. - Текст: электронный

4. Российская Федерация. Нормативные документы. Постановление Правительства от 26.06.1995 № 594 «О реализации Федерального закона "О поставках продукции для федеральных государственных нужд» - Доступ из справ.-правовой системы «Консультант-Плюс». - URL: http://www.consultant.ru/document/cons_doc_LAW_7120/92d969e26a4326c5d02fa79b8f9cf4994ee5633 b/. - Текст: электронный

5. Сайт Федеральные целевые программы России.- URL: https://fcp.economy.gov.ru/. - Текст: электронный

6. Сайт Федеральная адресная инвестиционная программа России.- URL: https://faip.economy.gov.ru/cgi/uis/faip.cgi/G1/ddoc/2020/. - Текст: электронный

7. Самофалова Е.В. Государственное регулирование национальной экономики [текст]: учеб. пособие под ред. / Е.В. Самофалова., под ред. Э.Н. Кузьбожева. - М.: КНОРУС, 2006. - 272 с.

8. Ялмаев Р.А. Финансирование федеральных целевых программ в условиях послевоенного восстановления экономики / Р. А. Ялмаев; Волг. гос. ун-т. - Волгоград: [б. и.], 2007. - 172 с.

\section{Людвиг Л.П., Самарин П.Н. \\ Состояние и тенденции развития экономической безопасности Сахалинской области}

Сахалинский институт железнодорожного транспорта, филиал ДВГУПС (Россия, Южно-Сахалинск)

doi: $10.18411 / \mathrm{j}-06-2021-276$

\section{Аннотация}

Статья посвящена оценке состояния и изучению проблем обеспечения экономической безопасности Сахалинской области.

Ключевые слова: анализ экономической безопасности субъекта РФ, Сахалинская область, интегральные и матричные методы анализа.

\section{Abstract}

The article is devoted to the assessment of the state and study of the problems of ensuring the economic security of the Sakhalin region.

Keywords: analysis of economic security of the subject of the Russian Federation, Sakhalin region, integral and matrix methods of analysis.

Изучение состояния и тенденций изменения экономической безопасности субъект РФ представляет значительный практический интерес для реализации стратегии обеспечения безопасности РФ на период до 2030 года, утвержденной указом президентом РФ В.В. Путиным от 13 мая 2017 года №208 [1].

Экономическая безопасность представляет собой сложное, многоаспектное явление, которое формируется в результате совместного влияния различных социально-экономических факторов.

Для оценки экономической безопасности Сахалинской области в 2015 - 2019 годах нами использована система из 21-го показателя, предложенная С.Ю. Глазьевым и И.В. Новиковой, которая адаптирована к показателям региональной статистики [2]. В таблице 1 представлены основные индикаторы состояния экономической безопасности Сахалинской области за 2015 - 2019 года, рассчитанные по данным Федеральной службы государственной статистики и конференции ООН по торговли и развитию [3] [5]. 